\title{
PROPUESTA DE ESTUDIO DEL DERECHO CONSTITUCIONAL DESDE LA RELECTURA DE LOS TEXTOS POLÍTICOS COMO DISCURSOS
}

\author{
Eloy García \\ Departamento de Derecho Constitucional \\ Facultad de Derecho \\ Universidad Complutense de Madrid \\ eloy.garcia@der.ucm.es
}

\begin{abstract}
RESUMEN
Se elabora una propuesta para incardinar los textos políticos discursivos dentro del mundo del Derecho constitucional, especialmente dentro de su enseñanza.

Palabras clave: Derecho constitucional, Constitución, discurso político, relato, narración, propuesta de estudio.
\end{abstract}

\section{ABSTRACT}

A proposal is drawn to provide for political discursive texts within the world of constitutional law, particularly within its study.

Keywords: Constitutional Law, Constitution, political speeches, story, storytelling, proposal of study.

\section{ZUSSAMENFASSUNG}

Die vorliegende Arbeit liefert einen Vorschlag, um die politischen Redetexte mit dem Bereich des Verfassungsrechts, besonders mit dem Bereich der Lebre, zu verknüpfen.

Schlüsselwörter: Verfassungsrecht, Verfassung, politischer Diskurs, Bericht, Erzählung, Untersuchungsvorschlag.

SUMARIO: I. NOTA EXPLICATIVA.-II. EL SENTIDO DE LOS DISCURSOS POLÍTICOS PARA EL DERECHO CONSTITUCIONAL.-III. ALGUNOS TEXTOS QUE SE PROPONE ESTUDIAR PARA ENCAMINAR LAS EXPLICACIONES A LOS ALUMNOS DE DERECHO CONSTITUCIONAL HACIA EL CONOCIMIENTO DE LOS PRINCIPALES PROBLEMAS QUE AQUEJAN A LA VIDA DEMOCRÁTICA Y A LA DIMENSIÓN CÍVICA DEL HOMBRE. 


\section{NOTA EXPLICATIVA}

José Antonio Alonso de Antonio fue un excelente profesor que proyectó su enorme bonhomía en una extraordinaria preocupación por los alumnos. Todos los que lo conocimos sabemos que una de sus grandes aficiones consistió en pasar largas horas atendiendo a cuantos estudiantes le pedían aclaraciones, ampliaciones o profundizar en las materias que explicaba y sobre otras muchas cosas. Incluso era bastante habitual que se dirigieran a su despacho en busca de consejo antiguos estudiantes que, habiendo concluido la licenciatura, necesitaban orientación en su futuro profesional. A todos los atendía con calma, afabilidad y entrega. Y lo hacía así porque le salía de muy dentro, porque ante todo era un profesor dedicado, un educador vocacional. Es decididamente esa faceta del profesor-educador, hoy convertida en una obligación burocrática ejercitada según técnicas virtuales que con frecuencia olvidan la identidad formativo-cultural de la docencia, la que me viene con más fuerza a la memoria en el momento de rendir homenaje a José Antonio. Tal vez sea una apreciación muy subjetiva y poco ponderada, que desconoce otras dimensiones de la personalidad académica e intelectual de un compañero no hace mucho desaparecido, pero considero importante insistir en esta faceta de nuestro amigo cuando la enseñanza parece cada día más encaminada a convertirse en una tarea en la que prima el saber técnico sobre los valores humanos.

Precisamente por esta razón, a la hora de incluir un trabajo en un número de la revista Foro destinado a recordar su memoria, me ha parecido adecuado redactar una pequeña contribución sobre una cuestión vinculada con la enseñanza del Derecho constitucional y la aportación que a su conocimiento pueden efectuar las nuevas orientaciones relacionadas con el pensamiento político, lo que se conoce como el discurso político. En el fondo, el objetivo es muy modesto. Lo que se pretende es poner de manifiesto que en la situación por la que actualmente atraviesa el Derecho constitucional es necesario recurrir a bastante más que a la norma y a los mecanismos que garantizan su eficacia para entender e intentar resolver los problemas de la vida política, que a fin de cuentas es el contenido final sobre el que versa nuestra disciplina. Para ello se sugiere algo tan simple como introducir en las explicaciones que se imparten al alumno a lo largo del curso, junto a la obligada construcción normativa, el estudio de un conjunto de textos que permitan captar desde el pensamiento el significado de los desafíos reales que aspira a resolver el Derecho constitucional. 
En este sentido, importa recordar - y es el dato fundamental a tener en cuenta- que esos textos, aunque son clásicos conocidos de mucho tiempo atrás, en su nueva condición de discursos se manifiestan ahora desde una luz interpretativa muy distinta que permite articular planteamientos que poco o nada tienen que ver con los interrogantes que tradicionalmente se entendía recogían. Son esos nuevos planteamientos los que posiblemente puedan servir para que un profesor con vocación pedagógica ayude al alumno a comprender mejor un Derecho constitucional que sepa ser contemporáneo de su propio tiempo histórico.

\section{EL SENTIDO DE LOS DISCURSOS POLÍTICOS PARA EL DERECHO CONSTITUCIONAL}

Vivimos épocas de grandes transformaciones que afectan al estudio de todos los ámbitos normativos, pero que en el campo del Derecho constitucional se aprecian de manera notablemente más acusada por dos clases de razones muy específicas:

- Por la revolución sin precedentes que en fechas recientes han sufrido las técnicas que abordan el análisis del pensamiento político y con ellas la forma de entender las grandes cuestiones fundamentales de la democracia, que incluso afectan a la misma concepción de la política que hasta hace poco resultaba generalmente admitida sin grandes objeciones.

- Por la evolución que ha seguido el Derecho constitucional en España y en la mayoría de las naciones democráticas, que de ciencia dotada de un considerable componente cultural ha pasado a ser concebida como una asignatura de naturaleza casi exclusivamente técnico-jurídica, centrada en la necesidad de imponer la fuerza normativa del Derecho y de asegurar su eficacia a través de mecanismos de tipo jurisdiccional.

Tiene bastante de paradójico el hecho de que al mismo tiempo que los caminos del cambio democrático llevaban al Derecho constitucional español a renunciar a su condición de disciplina sustancialmente política (Derecho político), en otros países ajenos a la tradición continental europea se fuera abriendo paso, de manera lenta pero incuestionablemente sólida, una vía nueva en el estudio de lo constitucional que, sin proponérselo explícitamente, señalaba todo un rumbo diferente para la renovación 
de nuestra materia y basado en una orientación acusadamente política de sus análisis. Me estoy refiriendo a los trabajos de la conocida como Escuela de Cambridge, integrada por profesores que dentro del ámbito anglosajón se interesaban por aquello que desde la perspectiva española se correspondía con la reflexión sobre los problemas de la teoría del Estado, la democracia y, en definitiva, de la dimensión social de lo político.

En los años cincuenta y sesenta del pasado siglo en Cambridge, dos estudiosos, Peter Laslett y John Pocock, se preocuparon de investigar dos textos de indudable transcendencia para el Derecho constitucional, el significado de la obra de John Locke, Segundo Tratado de Gobierno Civil, y los avatares que sufriría la categoría de Ancient Constitution en los siglos XVI y XVII. Tan importantes como las conclusiones a las que llegaron estos dos tratadistas, que también lo fueron y mucho (en concreto Laslett demostró que Locke no era el padre intelectual de la Revolución de 1689 y que su argumentación respondía al mundo de la religión y no al de la libertad política), lo sería el procedimiento que emplearon para llegar a ellas. Se trataba de una manera de enfocar el estudio de los textos que defendía el análisis concreto de lo que el autor había dicho en cada una de sus intervenciones específicas y que rompía con la regla de efectuar primero el emplazamiento sistemático de los pensadores del pasado dentro de una determinada corriente ideológica o escuela de ideas, para desde ese previo encasillamiento proceder a diseccionar su pensamiento trasladándolo luego a sus obras. Acababa de nacer el análisis del discurso político, cuyo punto de partida estaba en los textos escritos y la intencionalidad que expresaba cada documento. El texto y los problemas concretos que delataba y en los que se hallaba inmerso sustituía de alguna manera al autor, de modo que la historia del pensamiento, más que en una sucesión de personalidades y de sistemas de ideas, se configuraba como una suma encadenada de argumentos y contrargumentos (discursos) muy precisos, vinculados a asuntos absolutamente concretos y, por consiguiente, imposible de reconducir a una suma de esquemas intelectuales que tuvieron continuidad en el tiempo a modo de sucesivos conflictos de ideas.

El análisis de los discursos políticos, así pues, no es más que el estudio de los argumentos que el autor defiende en un texto, perfectamente definidos a través del examen del lenguaje que le permite expresarse y de la identificación de la conexión que mantiene con las razones invocadas en el pasado y con las que propugnan aquellos terceros a los que se opone y con quienes polemiza. Se pretende, por tanto, como se explicó, no encasillar al autor en un determinado modelo de pensamiento, sino analizar sus 
intervenciones texto a texto y procurar comprender cómo hablaba en cada ocasión, qué decía, con qué palabras lo hacía, contra quién iban dirigidas sus afirmaciones y cómo se había ido modulando su argumentación en el tiempo tanto en relación con lo que le habían legado sus predecesores como con respecto a lo que él mismo había venido sosteniendo anteriormente. En este sentido es fundamental llegar a detectar hasta qué punto un autor ha ido cambiado de vocabulario a medida que han pasado los años, y cómo ese vocabulario, nuevo o viejo, refleja la innovación o la continuidad del razonamiento que nutría su pensamiento y recogía los problemas a que pretendía hacer frente. Es a través de ese conjunto de referencias argumentales y semánticas desde donde se intenta reconstruir la línea discursiva que informa el pensamiento del autor respecto de un problema claramente definido y desde donde se busca entender qué propone un texto para afrontar la acción política.

Semejante nueva forma de plantear el estudio de lo que los autores del pasado han dicho ha implicado un cambio radical en el entendimiento del pensamiento político que desemboca en el nacimiento de la historiografía del discurso político (algo muy distinto de la historia de las ideas políticas) y ha tenido como consecuencia el cuestionamiento de alguna de las hasta entonces reputadas verdades intelectuales más incontrovertidas. Pero lo que cambió con ello no fue solo el enfoque del estudio del pensamiento del pasado, sino que, a mayores, el análisis de los discursos también ha significado toda una transformación de la comprensión de la política en clave de conciencia de presente y del modo de detectar sus problemas e intentar solucionarlos.

Y el cambio de enfoque es tan profundo - tan revolucionario- que ha ayudado a propiciar el desplazamiento del eje de gravedad de la reflexión política desde lo individual a lo colectivo, desde los derechos a los retos de la organización de la convivencia democrática. El problema antes que de libertad negativa pasa a ser ahora de libertad positiva. Más precisamente, la democracia se convierte en la cuestión central objeto de estudio y es entendida como la expresión de una cultura política en la que los hombres buscan autogobernarse ateniéndose a su dimensión colectiva y no a las situaciones subjetivas individuales y a sus garantías.

En este sentido, los estudiosos posteriores a los dos primeros exponentes de Cambridge, como Skinner, Dunn o Richard Tuck, consolidaron muy pronto lo que en un principio solo era una tendencia que apuntaba en el horizonte al tomar como objetivo de sus preocupaciones los diferentes discursos que convergieron en la construcción de la libertad republicana. 
Muchas son las implicaciones que se derivan de esta nueva forma de analizar el pensamiento. Aunque, a los efectos que aquí interesan, lo más transcendente de la aportación de esta escuela tal vez haya sido su capacidad de anticiparse al tiempo que estaba viniendo sin que quienes éramos sus contemporáneos nos apercibiéramos claramente de lo que estaba sucediendo. Y es que en plena Guerra Fría, cuando el mundo se debatía en una lucha entre dos ideologías radicalmente antagónicas que no dejaban espacio a ninguna opción alternativa, nadie pudo prever que la conclusión final sería la derrota de ambos contendientes por agotamiento de los principios ideológicos que los sostenían y como efecto de la defección del sistema de pensamiento que explicaba lo que los hombres estaban haciendo ante su falta de capacidad de comprensión de la realidad en que se hallaban inmersos.

Como evidencian, primero, la caída del muro de Berlín y, más tarde, la situación de descomposición que desde comienzos del siglo XXI se ha hecho patente en el mundo democrático, las ideologías que aspiraban a explicar las realidades políticas fueron perdiendo poco a poco sus contenidos hasta vaciarse y formalizarse por completo. Su fin vino marcado tanto por su esclerosis interna como por la degradación de las maneras de pensamiento que los propiciaron, que se hicieron viejas y se vieron sobrepasadas por las nuevas situaciones que irrumpieron en la vida. Bien es cierto que el pensamiento ideológico no era tan antiguo, que sus orígenes se remontaban solo al siglo XIX, pero su importancia resultaba capital porque había invadido en términos metodológicos y de concepción cualquier forma de expresión cultural, y fundamentalmente porque las ideologías habían construido el Estado constitucional y su Derecho.

Pero antes de que esto sucediera, y centrándonos en el estudio de nuestra disciplina, el problema se planteó en España cuando se produjo la estabilización definitiva del régimen democrático y cuando apuntaba de manera clara en el horizonte la necesidad de reorientar el estudio del Derecho constitucional desde el dato inexorable de la nueva Constitución democrática, momento en el que la pregunta que se suscitaba parecía obvia: ¿cómo fundamentar y explicar el Derecho constitucional de un Estado democrático una vez que sus soportes intelectuales y culturales habían cambiado tan radicalmente? Básicamente cabían tres opciones:

- Reducir al máximo la preocupación por sus presupuestos intelectuales y centrar el estudio de la materia en lo normativo concreto, entendiendo que ese es el verdadero cometido que cumple desa- 
rrollar a un jurista. Y en ese sentido, por ejemplo, las teorías neocontractualistas proporcionaban una óptima cobertura en la medida en que toda la reflexión en materia de pensamiento se conducía al único propósito de construir un consenso en el que fundamentar teóricamente el Derecho.

- Persistir en los viejos esquemas de nuestra disciplina manteniendo la vigencia de una teoría del Estado y un Derecho político de contenidos obsoletos en relación con la realidad efectiva de las cosas.

- Optar por intentar reconstruir una concepción de la política coherente con las necesidades problemáticas de la democracia de este tiempo y vincularla a una noción de Constitución integrada por dimensiones muy amplias, y no solamente ceñida al componente normativo.

Es evidente que nuestra doctrina se inclinó decididamente por una solución que se encuadraba dentro de la primera posibilidad en dos momentos sucesivos diferentes. Uno, el instante mismo de redactar la Constitución española de 1978. La Constitución española actual se configuraría en el pensamiento de sus autores y de los estudiosos que la modularon como un proyecto de estabilizar la política en y desde el Derecho. Se trataba de superar el fracaso histórico en nuestra institucionalización estatal precedente mediante un afianzamiento de la democracia en una constitución que recogía como gran valor la supremacía del Derecho. Un Derecho constitucional democrático debería ser capaz de conducir rígidamente nuestra sociedad por los senderos del respeto a los derechos fundamentales y del gobierno parlamentario. Pero es que, además, y en segundo lugar, la marcha de los acontecimientos, una vez se hubo puesto en funcionamiento el Tribunal Constitucional, dejó cerrada cualquier posibilidad de interpretar los problemas constitucionales en otra lógica que no fueran las leyes y el Derecho. El lenguaje jurídico desplazó las posibilidades de cualquier otra alternativa que apuntara en el horizonte, porque lo cifró todo en la posición de un tribunal que no creaba Derecho, sino que interpretaba una constitución que, por su parte, tenía atribuido el cometido de incorporar la novedad y el cambio a través de la reforma.

Como es sabido, hay quienes sostienen que el escaso recurso al mecanismo de reforma constitucional está en la causa de la falta de sintonía entre norma constitucional y realidad social que actualmente nos aqueja. Pero no es esa la cuestión que aquí interesa. De lo que se trata es de constatar que el entendimiento positivo-normativo del Derecho constitu- 
cional con el que se identifica la doctrina mayoritaria adolece de un obstáculo de fondo que consiste en la imposibilidad de reducir a norma toda la realidad constitucional y de encontrar respuestas a los problemas de la política exclusivamente en términos de lógica jurídica. Y no estamos ante una cuestión que afecte únicamente a la estructura territorial del Estado o incluso que pueda quedar restringida al problema de la integridad de la unidad nacional, sino que se extiende a los principales mecanismo que posibilitan la realización efectiva de la democracia. La cuestión es de democracia y no de ordenamiento jurídico. Consiste en cómo organizar la política y no en cómo reducirla a Derecho, y se proyecta en todos los ámbitos en los que los argumentos de la democracia tienen efectos: en el parlamento, en los partidos, en la vida local y hasta en la propia movilización que a la ciudadanía activa se le exige para mantener su condición de tal. No se sabe bien qué es la democracia, y como no se puede precisar su sustancia se recurre al socorrido procedimiento de habilitar un conjunto de mecanismos acreditativos formales para tratar de suponer su contenido a fuerza de simularlo. Pero la simulación de un contenido sustancial no equivale a poseer y comprender su identidad material. Por eso carecemos de argumentos políticos materiales y por eso el Derecho se mueve muchas veces en el vacío. Es muy difícil construir un Derecho constitucional sin tener clara una idea material de democracia, y todavía lo es más admitir una democracia sin un contenido político basado en la consciente implicación de todos en el gobierno de lo colectivo.

¿Cómo explicar la asignatura de Derecho constitucional en este contexto sin dejar de ser fiel al mismo tiempo a los deberes que impone una disciplina rigurosamente normativa y a las exigencias que dicta una realidad para la que la norma no resulte insuficiente? Posiblemente procurando estructurar internamente su estudio en dos partes y compaginando el examen de la Ley Fundamental en el apartado teórico con el análisis en la parte práctica de los textos de los autores que aportan argumentos concretos susceptibles de afrontar problemas que están a la altura de los tiempos. Es aquí donde cobra sentido el estudio de los discursos políticos como fórmula para imbricar la Constitución en la realidad. 


\section{ALGUNOS TEXTOS QUE SE PROPONE ESTUDIAR PARA ENCAMINAR LAS EXPLICACIONES A LOS ALUMNOS DE DERECHO CONSTITUCIONAL HACIA EL CONOCIMIENTO DE LOS PRINCIPALES PROBLEMAS QUE AQUEJAN A LA VIDA DEMOCRÁTICA Y A LA DIMENSIÓN CÍVICA DEL HOMBRE}

Concretamente se han venido considerando los textos que se mencionarán a continuación, en la creencia de que pueden ser útiles para que los alumnos reflexionen sobre los problemas que atañen a una constitución democrática y para hacerlo sobre argumentos que encierren posibles soluciones a los retos actuales. Lo que no quiere decir que se trate de una relación que tenga pretensiones de exhaustividad, sino únicamente indicativa y de carácter ejemplificador, establecida en el propósito de ilustrar con supuestos concretos lo que se está proponiendo.

En este sentido, importa recalcar, una vez más, que no se pretende sugerir una lectura de nuevos textos del pasado que sencillamente no existen, tan solo se puede acudir a aquellos que ya se conocen sobradamente. Lo que se intenta defender es la nueva lectura de los textos disponibles para investigar más cierta y concretamente sus argumentos desde los problemas que afrontan y no desde el teórico encuadramiento ideal que se atribuye al autor que los concibe. En definitiva, se aspira a llamar la atención sobre la urgencia de una «relectura» de los escritos de los clásicos para detectar en los viejos libros argumentos nuevos. La clave de la diferencia estriba en que ahora se busca estudiar los textos en su contexto discursivo de pasado y en el seno de la lógica argumental concreta que dio luz a cada escrito particular, porque desde ella se encuentran respuestas a nuestros problemas de presente que proceden del pasado. Estamos ante un fenómeno de enorme trascendencia que está cambiando muchas cosas y especialmente nuestro modo de entender una construcción del Derecho constitucional que se hace paulatinamente más histórica y menos ideal, más concreta y menos general, más micro-problemática y menos normativo-dirigente.

No es casual que en los últimos años los estudiosos de la historia del Derecho, como Fioravanti, Hespanha, Sotellis o los propios profesores de Cambridge, hayan cobrado tanto protagonismo en el terreno de lo constitucional. Nuca antes el Derecho constitucional los tuvo tan presentes y tampoco nunca como hoy necesitó tanto de su ayuda para comprender los desafíos políticos en que se encuentra sumido nuestro mundo. 
De cualquier forma esta es la relación que acompaña:

1. Maquiavelo. Se sugiere la lectura de su obra El Principe no para explicar desde ella el nacimiento del Estado, sino para poder llegar a plantearse dos problemas:

a) La dicotomía innovación/tradición en el pensamiento moderno y su incidencia en la forma de organizar el estudio de los argumentos políticos. Se trata de presentar al autor —en la lectura que hace John Pocock - como el primer gran pensador plenamente consciente del significado y las consecuencias que encerraba el hecho de innovar, de introducir lo nuevo.

b) Establecer como punto de ruptura entre nuestro mundo y el pasado no el momento del estallido de las revoluciones constitucionales del siglo XVIII, sino el tiempo de la paulatina sustitución de la cultura de los antiguos por la cultura de los modernos. Algo que explicó muy bien en su día Lewis Mumford.

2. Diferentes textos seleccionados de Tomas Hobbes (además de Leviathan, De Cive, Diálogo entre un jurista y un filósofo y Elementos de Derecho) para evidenciar que —como enseña Richard Tuck- fue el primer autor decididamente moderno, es decir, el primero en pensar la política en clave de sociedad y no de poder descendente. Hobbes es el gran autor del argumento de la legitimidad que rechaza la soberanía (nos lo explica Martin Kriele), un pensador extraordinariamente preocupado por articular en términos jurídicos la vida colectiva.

3. El libro de Bernard Bailyn, Los orígenes ideológicos de la Revolución norteamericana, para poder examinar dos problemas:

a) Cómo un proceso de regeneración se transforma en una revolución, esto es, de cómo existen dos vías alternativas de cambio en política, la innovación en la continuidad y la ruptura radical con el pasado y la consiguiente irrupción del poder constituyente. Se pretende contraponer las categorías de crisis (Koselleck) con las de corrupción/degradación (Montesquieu).

b) Comprender cómo el paso de una a otra concepción se opera en un tiempo concreto y captar de qué manera la sustitución de una por otra puede llevar a los hombres a obrar políticamente de forma diferente creando una nueva organización constitucional nacida de la nada política. 
Asociado a ello se sugiere, asimismo, estudiar el libro de Antonio La Pergola, Vestigios «contractualistas» y estructura federal en la Constitución de los Estados Unidos, sobre el origen de la experiencia constitucional norteamericana y la construcción de la unidad federal con base en la idea de consenso, manifestación del argumento de la legitimidad y expresión de la superación de la categoría de contrato.

4. Diferentes textos jurídicos de Kant, Pagano (el primer autor en definir la reforma constitucional) y Filangieri para examinar en detalle el discurso que construye la idea ilustrada de ley como expresión superior del Derecho. Es importante vincular este argumento con las fuentes del Derecho y todos sus procederes y estructuras formales. El contraste con los problemas actuales de la realidad normativa sirve para evidenciar dónde nos encontramos en el terreno de la lógica jurídica más pura y los límites de su capacidad reguladora de la política.

5. Los dos textos que enfrentan a Kant con Benjamin Constant en su polémica sobre si ¿hay derecho a mentir?, entendida no como un conflicto en torno a la verdad, sino como un debate acerca de si existen o no principios universales irrenunciables que puedan resultar válidos en cualquier sociedad y tiempo. La construcción de la categoría de principio como valor absoluto o relativo socialmente determinable está detrás de ambas argumentaciones. En el fondo se trata de una polémica sobre las posibilidades de reducir a la unidad una pluralidad de valores y darles estabilidad, continuidad en el tiempo.

6. Los dos textos sobre la defensa de la constitución escritos por Kelsen y Carl Schmitt para analizar no los pros y contras de la justicia constitucional, sino las circunstancias políticas y sociales en que se optó por buscar una institución encargada de velar porque la constitución se cumpliera. Lo importante es analizar los argumentos que confluyen en la definición de la constitución como democrática y determinar qué significa el pluralismo para muestra idea de democracia. Por eso el estudio de estos argumentos debería ser acompañado de la lectura del libro de Kelsen, Esencia $y$ valor de la democracia.

7. La lectura del texto de Alain, El ciudadano contra los poderes, que ofrece la posibilidad de conocer los argumentos del discurso republicano en dos ámbitos: el debate entre política y poder, entre democracia y obediencia, y la lucha por la libertad de pensamiento y la necesidad de que el ciudadano construya su propia conciencia. Asociado a este libro sería muy oportuno incorporar el trabajo de Peter Mair, Gobernando el vacío, para, desde una lectura complementaria que atiende a la dimensión inter- 
na de los partidos, poner de manifiesto las consecuencias del desfondamiento de las ideologías sobre los mecanismos organizativos que estructuraban la democracia constitucional y su sustitución por nuevas formas de poder que renuncian a invocar argumentos políticos y los remplazan por imágenes.

8. La lectura del libro de Max Aub, La Gallina Ciega, por tratarse de un texto literario que da fe de los argumentos que se manejaban en Españas en los años inmediatamente anteriores a la transición política y que permiten comprender los fondos culturales y políticos sobre los que se construyó nuestra Constitución de 1978. La referencia a esta obra literaria hace posible, además, participar al alumno de la existencia de un discurso político muy importante en la literatura española, que fue particularmente útil para el conocimiento de la política cuando no había construcción jurídica de la sociedad a que acogerse.

Resulta obvio que una propuesta integrada por tantos textos pueda terminar resultando inabordable para el alumno dada la breve duración del curso y la cantidad de materias que debe cursar cada semestre. Pero habida cuenta de que el Derecho constitucional es una asignatura que abarca dos semestres y que, obviamente, el número de lecturas puede muy bien resultar ampliado o reducido en función de las necesidades y conveniencias de las clases, se incluye un elenco bastante extenso de textos en la convicción de que esa relación resulta susceptible de ser más o menos agotada. En cualquier caso, se trata de acreditar que junto al análisis normativo de lo constitucional debe acompañar siempre un estudio de lo político, porque en la realidad ambos se presentan como dos componentes inseparablemente entrelazados. El conocimiento de los argumentos concretos que los hombres emplean en la vida para afrontar esos problemas es parte efectiva de lo constitucional y a ese conocimiento es a lo que se denomina estudio del discurso político. 